\title{
Addition of eGFR and Age Improves the Prognostic Absolute Renal Risk-Model in 1,134 Norwegian Patients with IgA Nephropathy
}

\author{
Thomas Knoop ${ }^{a, b} \quad$ Ann Merethe Vågane ${ }^{a} \quad$ Bjørn Egil Vikse ${ }^{a, c} \quad$ Einar Svarstad $^{a, b}$ \\ Bergrún Tinna Magnúsdóttir ${ }^{\mathrm{e}}$ Sabine Leh ${ }^{\mathrm{a}, \mathrm{d}} \mathrm{f} \quad$ Anna Varberg Reisæter ${ }^{\mathrm{g}}$ \\ Rune Bjørneklett ${ }^{\mathrm{a}, \mathrm{b}}$ \\ ${ }^{a}$ Renal Research Group, Department of Clinical Medicine, University of Bergen, ${ }^{b}$ Department of Medicine, \\ Haukeland University Hospital, Bergen, ${ }^{\mathrm{C}}$ Department of Medicine, Haugesund Hospital, Haugesund, ${ }^{\mathrm{d}}$ Department \\ of Pathology, Haukeland University Hospital, Bergen, ${ }^{e}$ Competence Centre for Clinical Research, Haukeland \\ University Hospital, Bergen, ${ }^{\mathrm{f}}$ Department of Clinical Medicine, The Gade Laboratory for Pathology, University of \\ Bergen, ${ }^{9}$ Norwegian Renal Registry, Section of Nephrology, Department of Transplant Medicine, Oslo University \\ Hospital, Rikshospitalet, Oslo, Norway
}

\section{Key Words}

End-stage renal disease $\cdot$ Immunoglobulin A nephropathy · Mortality · Prognosis · Risk factor

\begin{abstract}
Background: Predicting outcome in individual patients with $\operatorname{Ig}$ A nephropathy (IgAN) is difficult but important. For this purpose, the absolute renal risk (ARR) model has been developed in a French cohort to calculate the risk of end-stage renal disease (ESRD) and death. ARR (0-3) is scored in individual IgAN patients based on the presence of proteinuria $\geq 1 \mathrm{~g} / 24 \mathrm{~h}$, hypertension, and severe histopathological lesions (1 point per risk factor). We have validated the ARR model in a Norwegian cohort of IgAN patients and tested whether adding data on initial estimated glomerular filtration rate (eGFR) and age improved prediction. Methods: IgAN patients diagnosed between 1988 and 2012 were identified in the Norwegian Kidney Biopsy Registry, and endpoints were identified by record linkage with the Norwegian Renal Registry (ESRD) and the Population Registry (deaths). Results: We identified 1,134 IgAN patients. The mean duration of follow-up was 10.2 years (range 0.0 to 25.7 years). Two
\end{abstract}

hundred and fifty one patients developed ESRD and there were 69 pre-ESRD deaths. The ARR model significantly stratified the IgAN cohort according to risk of ESRD/death. The inclusion of eGFR and age significantly improved the ARR prognostic model; in the receiver operator characteristics (ROC) analysis, area under the curve (AUC) at 10-years of follow-up increased from 0.79 to $0.89, p<0.001$. Conclusions: ARR is a suitable prognostic model for stratifying IgAN patients according to the risk of ESRD or death. Including initial eGFR and age in the model substantially improved its accuracy in our nationwide cohort.

(c) 2015 S. Karger AG, Basel

\section{Introduction}

Immunoglobulin A nephropathy (IgAN) is generally considered the most frequently occurring primary glomerulonephritis in the world [1-3], and prognostic aspects of the disease are of great interest for nephrologists and researchers. The clinical outcome of IgAN is variable, ranging from minor and stable asymptomatic disease to progressive renal failure and end-stage renal disease (ESRD)

\begin{tabular}{ll}
\hline KARGER 125: & $\begin{array}{l}\text { (1) 2015 S. Karger AG, Basel } \\
\text { 0250-8095/15/0413-0210\$39.50/0 Openger }\end{array}$ \\
$\begin{array}{l}\text { E-Mail karger@karger.com } \\
\text { www.karger.com/ajn }\end{array}$ & $\begin{array}{l}\text { This is an Open Access article licensed under the terms of the } \\
\text { Creative Commons Attribution-NonCommercial 3.0 Un- } \\
\text { ported license (CC BY-NC) (www.karger.com/OA-license), } \\
\text { applicable to the online version of the article only. Distribu- } \\
\text { tion permitted for non-commercial purposes only. }\end{array}$
\end{tabular}

Thomas Knoop

Department of Medicine

Haukeland University Hospital

NO-5021 Bergen (Norway)

E-Mail Thomas.knoop@gmail.com 
[4-6]. Identification of single risk factors in IgAN patients is valuable and has received considerable attention [7-13]; however, a combination of different risk factors is potentially even more useful, and a few models incorporating multiple factors have been published in recent years [4-6, $14,15]$. A reliable and widely generally accepted prognostic model can aid the nephrologist when informing the patient about the expected prognosis and deciding on follow-up and treatment regimens. Furthermore, prognostic stratification is important when IgAN patients are included in clinical studies and in the comparison of outcome in different IgAN cohorts. In a recent review, Barbour and Reich demonstrated that various prognostic models of IgAN have been developed in cohorts with considerable differences, for example, number of included patients, length of follow-up, and selection of endpoints and risk factors are highly variable [4]. In addition, to gain general acceptance, external validation of prognostic models is necessary before implementation in clinical practice [16].

Recently, Berthoux et al. published the new prognostic absolute renal risk (ARR) model to predict ESRD or death in IgAN patients [14]. This model is based on the presence or absence of hypertension, proteinuria $\geq 1 \mathrm{~g} / 24 \mathrm{~h}$, and severe histopathological renal lesions. Based on these risk factors, IgAN patients are stratified into four categories with an ARR score from 0-3 points. This model is simple to use, and the primary endpoint of ESRD or death is highly clinically significant. Of note, a well-established risk factor in IgAN patients, initial estimated glomerular filtration rate (eGFR) [4-6, 17], is not included in this model. Neither is age, which is a very strong predictor for death and generally patients with chronic kidney disease (CKD) stage 3-5 consist of older patients than patients with CKD stage 1 or $2[15,20]$.

We have tested the validity of the ARR model in a nationwide cohort of 1,134 IgAN patients from the Norwegian Kidney Biopsy Registry with up to 25 years of follow-up. We hypothesized that ARR would be useful in the Norwegian IgAN cohort but that including initial eGFR and age in the model would further improve its accuracy.

\section{Subjects and Methods}

The study was approved by the Regional Ethics Committee.

Registries Used in the Present Study

The Norwegian Kidney Biopsy Registry (NKBR) was established in 1988 and has collected clinical, biochemical, immunological, and morphological data from most patients who have had a kidney biopsy performed in Norway (current population, 5.1 million) since 1988. All kidney biopsies are evaluated by an experienced nephropathologist. The Norwegian Renal Registry is located at Oslo University Hospital, Rikshospitalet, Norway. All patients in Norway starting chronic renal replacement therapy (chronic dialysis treatment or kidney transplant) have been registered since 1980. The Norwegian Population Registry is part of the tax office in Norway, all Norwegian citizens are registered with a unique 11-digit personal number, and all deaths are registered on a weekly basis.

\section{Identification of Patients with IgAN}

We identified all patients diagnosed with primary IgAN and included in NKBR in the period from 1988-2012. The diagnosis of IgAN was based on the criteria described in a World Health Organization monograph of renal disease [18].

\section{Method of Follow-Up and Definition of Endpoint}

The observation period was defined as the period between the date of the kidney biopsy and ESRD (commencement of renal replacement therapy in the form of maintenance dialysis treatment or kidney transplantation), death, or the end of June 2013, whichever came first. The primary endpoint of the present study was ESRD or death. ESRD and death were identified by record linkages of the study cohort with the Norwegian Renal Registry and the Norwegian Population Registry. Only deaths prior to the development of ESRD were counted as endpoints in the present study. In separate analyses of risk of ESRD, death prior to ESRD was treated as a censoring event. In separate analyses of risk of preESRD death, ESRD was treated as a censoring event. We classified causes of death as cardiovascular disease, malignant disease, infectious disease, or other disease/accident.

\section{Prognostic Factors Used in the Study}

Proteinuria $<v s . \geq 1 \mathrm{~g} / 24 \mathrm{~h}$. Proteinuria was measured quantitatively in $80 \%$ of cases. In $16 \%$ of the patients proteinuria was semi-quantified with a standard urine dipstick with $(-),(+),(++)$ and $(+++)$ corresponding to $<30,30-99,100-299$ and $\geq 300 \mathrm{mg} /$ $\mathrm{dl}$ of urine albumin [19]. The result was converted as follows: $\leq 1+=<1 \mathrm{~g} / 24 \mathrm{~h}$ and $\geq 2+=\geq 1 \mathrm{~g} / 24 \mathrm{~h}$ [17]. When neither quantitative nor dipstick measurements were available (4\% of patients), the notification of indication for biopsy on the Kidney Biopsy Registry report form was used. When the answer to the question 'proteinuria and nephrotic syndrome yes/no' was 'no', proteinuria was set to $<1 \mathrm{~g} / 24 \mathrm{~h}$; if the answer was 'yes', proteinuria was set to $\geq 1 \mathrm{~g} / 24 \mathrm{~h}$.

Hypertension. We defined hypertension as measured blood pressure (BP) $\geq 140 / 90 \mathrm{~mm} \mathrm{Hg}$ or use of antihypertensive treatment; these data were available in $95 \%$ of the patients. In cases with missing data on blood pressure $(<5 \%)$, the notification of indication for biopsy on the Kidney Biopsy Registry report form was used and based on the answer to the question 'hypertension yes/no'.

Histological Characteristics. We used a similar definition of mild or severe histopathological lesions as previously reported [20]. Severe lesions were defined as follows: adhesions/segmental sclerosis/crescents/global sclerosis in more than $10 \%$ of the glomeruli OR interstitial inflammation/fibrosis in more than $25 \%$ of the biopsy area OR significant vasculopathy.

Estimated GFR (eGFR). We used the Chronic Kidney Disease Epidemiology Collaboration formula (CKD-EPI) to calculate the 
Table 1. Cohort characteristics at the time of IgAN diagnosis stratified by the initial estimated glomerular filtration rate (eGFR)

\begin{tabular}{lllll}
\hline Variable & \multicolumn{3}{l}{ Initial eGFR $\left(\mathrm{ml} / \mathrm{min} / 1.73 \mathrm{~m}^{2}\right)$} & \\
\cline { 2 - 5 } & $\begin{array}{l}\text { All } \\
(\mathrm{n}=1,134)\end{array}$ & $\begin{array}{l}\geq 60 \\
(\mathrm{n}=702)\end{array}$ & $\begin{array}{l}30-59.9 \\
(\mathrm{n}=264)\end{array}$ & $\begin{array}{l}<30 \\
(\mathrm{n}=168)\end{array}$ \\
\hline Mean (SD) age, years & $38(16)$ & $32(13)$ & $45(15)$ & $53(17)$ \\
Age $\geq 60$ years & $137(12)$ & $19(3)$ & $49(19)$ & $69(41)$ \\
Male (\%) & $829(73)$ & $507(72)$ & $196(74)$ & $126(75)$ \\
Proteinuria $\geq 1 \mathrm{~g} / 24 \mathrm{~h}(\%)$ & $684(60)$ & $378(54)$ & $183(69)$ & $123(73)$ \\
Hypertension $(\%)$ & $411(36)$ & $170(25)$ & $132(50)$ & $107(64)$ \\
Severe histopathological lesions $(\%)$ & $749(66)$ & $374(53)$ & $220(83)$ & $155(92)$ \\
\hline
\end{tabular}

$\mathrm{SD}=$ Standard deviation

eGFR from serum creatinine. We stratified patients based on eGFR data into three groups: $\geq 60,30-60$, and $<30 \mathrm{ml} / \mathrm{min} / 1.73 \mathrm{~m}^{2}$.

Age. Patients were stratified according to age $<60$ vs. $\geq 60$ years.

\section{Scoring of Patients According to ARR}

Patients were scored according to the number of risk factors (proteinuria $\geq 1 \mathrm{~g} / 24 \mathrm{~h}$, hypertension, $\mathrm{BP} \geq 140 / 90$, and severe pathological lesions; 1 point for each risk factor) into four risk groups (ARR score 0-3).

\section{Modified ARR Model}

The modified ARR model is based upon the risk factors from the original ARR model (proteinuria, hypertension and severe histopathological lesions), and also including eGFR data divided into three groups: $\geq 60,30-60$, and $<30 \mathrm{ml} / \mathrm{min} / 1.73 \mathrm{~m}^{2}$ and age: $<60$ vs. $\geq 60$ years. The importance or weight of each risk factor in the modified ARR model is derived from the adjusted Hazard Ratios (HR) estimated by a Cox proportional hazard model. The modified ARR score for each patient is calculated by multiplying the adjusted HR associated with each of the 5 risk factors if present, mathematical formula shown in online supplementary figure 1 (www.karger.com/doi/10.1159/000381403). Example: For proteinuria $\geq 1 \mathrm{~g} / 24 \mathrm{~h}$ and severe histopathological picture, we derived $\mathrm{HR}=2.1$ and 2.4, respectively. Consequently, a patient with these but no other risk factors present has a modified ARR score of 5.0 $(2.1 \times 2.4)$.

Furthermore, the study cohort was risk stratified into 6 groups using the log-transformed modified ARR score. Risk group A; log score $=0$, group $B$; $\log$ score $>0-<1$, group $C$; $\log$ score $\geq 1-<2$, group $\mathrm{D}$; $\log$ score $\geq 2-<3$, group $\mathrm{E}$; $\log$ score $\geq 3-<4$ and group $\mathrm{F}$; $\log$ score $\geq 4-<5$.

\section{Statistical Analyses}

Statistical analyses were performed using the statistical software SPSS Statistics 22 (SPSS Inc.). All statistical analyses were two-tailed, and a significance level of 0.05 was treated as statistically significant. First, we tested whether the Cox proportional hazard model fitted the data well and that the proportional hazard assumption was not violated. Second, we calculated the unadjusted and adjusted HRs for ESRD or death for each prognostic component in the ARR concept and for eGFR 30-60 and $<30 \mathrm{ml} /$ $\min / 1.73 \mathrm{~m}^{2}$ and age $\geq 60$ years. Third, using Kaplan-Meier statistics, we calculated the cumulative risk of ESRD or death after 5 and 15 years of follow-up in each ARR group and modified ARR group. Log-rank tests were used to test statistical significance. Third, receiving operating characteristic (ROC) curves were used to evaluate the performance of the ARR and the modified ARR models. We derived ROC curves and calculated the area under the curve (AUC) for 5, 10, and 15 years survival excluding observations censored before 5 respectively 10 and 15 years follow-up. Fourth, we calculated the number of patients needed to follow (NNTF) in the different risk groups of the ARR and the modified ARR model. NNTF can be defined as how many patients are needed to follow to detect one patient with endpoint. Fifth, we calculated the consequences of not following one or several low risk groups. Finally, we compared the French and Norwegian study cohorts regarding the distribution of patients in each ARR group and with initial eGFR $<60 \mathrm{ml} / \mathrm{min} / 1.73 \mathrm{~m}^{2}$. In the French cohort, time zero preceded the diagnostic biopsy with a mean of 5.5 years. Therefore and as further explained in the discussion section, cumulative risks of dialysis/death 5 and 15 years after kidney biopsy were compared with 10 and 20 years outcome respectively in the French cohort.

\section{Results}

We identified 1,134 IgAN patients. Of this cohort, 251 (22\%) developed ESRD, and 69 (6\%) died prior to ESRD. Causes of death were cardiovascular disease (45\%), malignant disease (16\%), infectious disease $(19 \%)$, or other disease/accident (20\%). The mean duration of follow-up was 10.2 years (minimum 0.0 , maximum 25.7 years). The mean age at time of IgAN diagnosis was 38 years (standard deviation, 16 years), and $73 \%$ of patients were males. Further cohort characteristics stratified for groups of baseline eGFR are shown in table 1.

The Cox proportional hazard model fitted the data well, all risk factors were significant, and the proportion- 
Table 2. Unadjusted and adjusted* HR for ESRD or death for components of ARR, initial eGFR and age

\begin{tabular}{|c|c|c|c|c|}
\hline & $\begin{array}{l}\text { Total } \\
\mathrm{n}(\%)\end{array}$ & $\begin{array}{l}\text { ESRD/deaths } \\
\mathrm{n}(\%)\end{array}$ & $\begin{array}{l}\text { Unadjusted HR } \\
(95 \% \mathrm{CI})\end{array}$ & $\begin{array}{l}\text { Adjusted HR } \\
(95 \% \mathrm{CI})\end{array}$ \\
\hline \multicolumn{5}{|l|}{ Proteinuria } \\
\hline$<1 \mathrm{~g} / 24 \mathrm{~h}$ & $450(40)$ & $80(18)$ & 1.0 & 1.0 \\
\hline$\geq 1 \mathrm{~g} / 24 \mathrm{~h}$ & $684(60)$ & $240(35)$ & $2.9(2.2-3.7)$ & $2.1(1.6-2.7)$ \\
\hline Not hypertension & $723(64)$ & $141(20)$ & 1.0 & 1.0 \\
\hline Hypertension & $411(36)$ & $179(44)$ & $2.9(2.3-3.6)$ & $1.4(1.1-1.7)$ \\
\hline No severe histopathological lesions & $385(34)$ & $51(13)$ & 1.0 & 1.0 \\
\hline $\begin{array}{l}\text { Severe histopathological lesions } \\
\text { eGFR } \mathrm{ml} / \mathrm{min} / 173 \mathrm{~m}^{2}\end{array}$ & $749(66)$ & $269(36)$ & $5.2(3.8-7.2)$ & $2.4(1.7-3.3)$ \\
\hline$\geq 60$ & $702(62)$ & $77(11)$ & 1.0 & 1.0 \\
\hline $30-59.9$ & $264(23)$ & $122(46)$ & $5.7(4.3-7.6)$ & $3.7(2.8-5.1)$ \\
\hline$<30$ & $168(15)$ & $121(72)$ & $18.7(14.1-25.2)$ & $11.3(8.1-15.7)$ \\
\hline \multicolumn{5}{|l|}{ Age, years } \\
\hline$<60$ & $997(88)$ & $233(23)$ & 1.0 & 1.0 \\
\hline$\geq 60$ & $137(12)$ & $87(64)$ & $4.6(3.6-5.9)$ & $1.4(1.1-1.9)$ \\
\hline
\end{tabular}

* Adjusted for all other risk factors (proteinuria, hypertension, severe pathological lesions, eGFR, and age $\geq 60)$. CI = Confidence interval.

al hazard assumption did not seem to be violated. As also shown in table 2, adjusted HRs were as follows: proteinuria $\geq 1 \mathrm{~g} / 24 \mathrm{~h}, 2.1$; hypertension, 1.4 ; severe histopathological lesions, 2.4; eGFR $30-60 \mathrm{ml} / \mathrm{min} / 1.73 \mathrm{~m}^{2}, 3.7$; eGFR $<30 \mathrm{ml} / \mathrm{min} / 1.73 \mathrm{~m}^{2}, 11.3$ and age $\geq 60$ years, 1.4 .

At 5 and 15 years of follow-up respectively, the cumulative risk of ESRD or death was 3 and $6 \%$ with an ARR score of $0 ; 6$ and $21 \%$ with an ARR score of $1 ; 17$ and $43 \%$ with an ARR score of 2; and 39 and $60 \%$ with an ARR score of 3 . These data, as well as data on cumulative risk of ESRD and death prior to ESRD separately, are shown in table $3 \mathrm{a}$ and figure 1.

In the modified ARR model, the scores ranged from 1.0 to 111.6. Stratification of the scores into six groups (A-F) equally spaced on a logarithmic scale is shown in table $3 \mathrm{~b}$.

The cumulative risk of ESRD or death at 5 and 15 years respectively was 1 and 3\% in group A, 3 and $11 \%$ in group B, 8 and $25 \%$ in group C, 15 and $55 \%$ in group D, 37 and $77 \%$ in group E, and 74 and $88 \%$ in group F. These data, as well as data on cumulative risk of ESRD and death prior to ESRD separately, are shown in table 3a and figure 2.

In ROC analyses, AUC values at 5, 10, 15 years were $0.76,0.79,0.80$, respectively with the original ARR model and $0.88,0.89,0.88$, respectively with the modified ARR model (score 1-111.6) in this cohort, the differences being highly statistically significant, $\mathrm{p}<0.001$ (fig. 3a-c).
AUC in ROC analyses after stratification into the risk group A-F did not change.

As shown in table 4, NNTF was 16.7 with ARR 0, 4.8 with ARR 1, 2.3 with ARR 2 and 1.7 with ARR 3. In the modified ARR model, NNTF was 33.3 in risk group A, 9.1 in group $\mathrm{B}, 4.0$ in group C, 1.8 in group $\mathrm{D}, 1.3$ in group $\mathrm{E}$, and 1.2 in group $F$.

The consequences of defining low risk groups as nonspecialist candidates for follow-up are shown in table 4 . Applying the original ARR model, excluding group 0 from follow-up results in 185 (16\%) less patients and still $96 \%$ of end-points detected. Excluding group 0 and 1 results in 499 (44\%) fewer patients with detection rate of end-points of 78\%. Applying the modified ARR model, excluding group A from follow-up results in 168 (15\%) less patients with detection rate of end-points of $98 \%$. Excluding group A and B results in 394 (35\%) fewer patients to follow and detection rate of end-points of $91 \%$.

Table 5 provides a comparison of the French [14] and Norwegian cohorts. The most important baseline difference was that the Norwegian cohort had more patients with initial eGFR $<60 \mathrm{ml} / \mathrm{min} / 1.73 \mathrm{~m}^{2}$ (38 vs. $26 \%$ ). In general, Norwegian patients also had higher ARR scores, $50 \%$ having an ARR score of $2-3$ vs. $34 \%$ in the French cohort. Five years after the kidney biopsy, the risks of ESRD/death were 2\% (French) versus 3\% (Norwegian) in patients with ARR 0, 2 vs. $6 \%$ with ARR 1,7 vs. $17 \%$ with ARR 2 and 29 vs. 39\% with ARR 3. Fifteen years 
Table 3.

a Cumulative risk of the combined primary endpoint, ESRD and pre-ESRD death, in different ARR score groups, stratified by eGFR values

\begin{tabular}{|c|c|c|c|c|c|c|c|c|c|c|c|}
\hline & \multirow[t]{2}{*}{$\begin{array}{l}\text { ARR } \\
\text { groups }\end{array}$} & \multirow[t]{2}{*}{$\begin{array}{l}\text { Total, } \\
\mathrm{n}\end{array}$} & \multirow{2}{*}{$\begin{array}{l}\text { ESRD } \\
\text { or death, } \\
\mathrm{n}(\%)\end{array}$} & \multirow[t]{2}{*}{$\begin{array}{l}\text { ESRD, } \\
\mathrm{n}(\%)\end{array}$} & \multirow[t]{2}{*}{$\begin{array}{l}\text { Pre-ESRD } \\
\text { death, n (\%) }\end{array}$} & \multicolumn{2}{|c|}{$\begin{array}{l}\text { Cumulative risk } \\
\text { ESRD or death, \% }\end{array}$} & \multicolumn{2}{|c|}{$\begin{array}{l}\text { Cumulative risk } \\
\text { ESRD, \% }\end{array}$} & \multicolumn{2}{|c|}{$\begin{array}{l}\text { Cumulative risk } \\
\text { pre-ESRD death, } \%\end{array}$} \\
\hline & & & & & & 5 years & 15 years & 5 years & 15 years & 5 years & 15 years \\
\hline \multirow{3}{*}{$\begin{array}{l}\text { Original } \\
\text { ARR } \\
\text { model }\end{array}$} & 0 & 185 & $14(8)$ & $11(6)$ & $3(2)$ & 3 & 6 & 2 & 5 & 1 & 1 \\
\hline & 1 & 314 & 57 (18) & $40(13)$ & $17(5)$ & 6 & 21 & 4 & 15 & 2 & 6 \\
\hline & 2 & 375 & $116(31)$ & $93(25)$ & $23(6)$ & 17 & 43 & 14 & 36 & 3 & 11 \\
\hline \multirow{6}{*}{$\begin{array}{l}\text { Modified } \\
\text { ARR } \\
\text { model }^{*}\end{array}$} & A & 168 & $6(4)$ & $6(4)$ & $0(0)$ & 1 & 3 & 1 & 3 & 0 & 0 \\
\hline & $\mathrm{B}$ & 226 & $23(10)$ & $20(9)$ & $3(1)$ & 3 & 11 & 3 & 10 & 0 & 1 \\
\hline & $\mathrm{C}$ & 318 & $54(17)$ & $43(14)$ & $21(7)$ & 8 & 25 & 6 & 21 & 2 & 5 \\
\hline & $\mathrm{D}$ & 169 & $65(38)$ & $48(28)$ & $10(6)$ & 15 & 55 & 10 & 47 & 5 & 15 \\
\hline & $\mathrm{E}$ & 134 & $79(59)$ & $57(43)$ & $18(13)$ & 37 & 77 & 29 & 66 & 12 & 32 \\
\hline & $\mathrm{F}$ & 119 & $93(78)$ & $77(65)$ & $17(14)$ & 74 & 88 & 66 & 82 & 23 & 31 \\
\hline
\end{tabular}

* Table $3 \mathrm{~b}$ shows the stratification of cohort based on modified ARR model.

b Stratification of cohort based on modified ARR model

\begin{tabular}{lll}
\hline Risk group & Modified ARR score & log modified ARR score \\
\hline A & 1.0 & $>0-<1$ \\
B & $1.4-2.4$ & $\geq 1-<2$ \\
C & $2.9-7.3$ & $\geq 2-<3$ \\
D & $7.8-18.6$ & $\geq 3-<4$ \\
E & $22.1-53.2$ & $\geq 4-<5$ \\
F & $57.0-111.6$ & $>0-<1$ \\
\hline
\end{tabular}

* Modified ARR score can be calculated by multiplying the adjusted Hazard Ratios given in table 2.

Example: For proteinuria $\geq 1 \mathrm{~g} / 24 \mathrm{~h}$ and severe histopathological picture we derived $\mathrm{HR}=2.1$ and 2.4 , respectively. Consequently a patient with these but no other risk factors present has a modified ARR score of $5.0(2.1 \times 2.4)$.

after biopsy the numbers were $4 \%$ (French) versus $6 \%$ (Norwegian) in patients with ARR 0,9 vs. $21 \%$ with ARR 1,18 vs. $43 \%$ with ARR 2 and 64 vs. $60 \%$ with ARR 3.

\section{Discussion}

The major findings in the present study are that ARR is suitable to predict ESRD and death in Norwegian IgAN patients, confirming the findings of Berthoux et al. [14], and that including initial eGFR and age in our study significantly increases the accuracy of the model. The ROC analyses show that the original ARR model can be characterized as a fair prognostic model, whereas the new modified ARR model improved the prognostic capacity in our cohort. We have also shown that all components of the ARR concept are independent risk factors for ESRD and death in our IgAN patients and probably should be included in any prognostic model of this disease.

Our findings are not surprising given the facts that proteinuria, hypertension, initial eGFR, and histopathological lesions are the four best documented traditional risk markers for progression to ESRD $[4-6,17]$ and death in IgAN patients [21]. In principle, all prognostic models should be tested on populations that are independent of the cohort used to develop the models [16]. To our knowledge the ARR model has previously only been validated on one external cohort, 74 patients with Henoch-Schönleins purpura [22], and the results of the present study therefor substantially increases the generalizability of the 


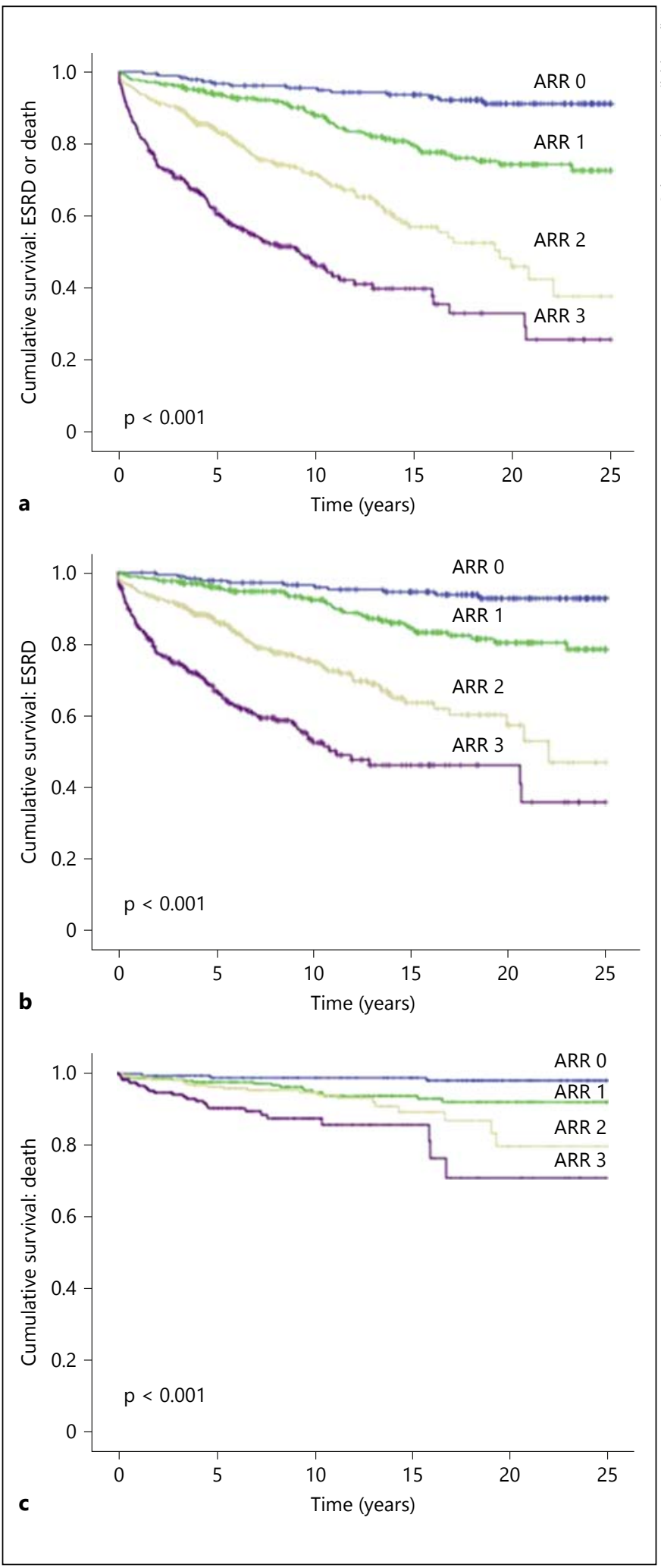

Fig. 1. a-c Kaplan-Meier plots showing cumulative risk of endstage renal disease (ESRD) or death in each absolute risk group $(\mathrm{ARR})$ in the original ARR model (a), ESRD (b), and death (c).

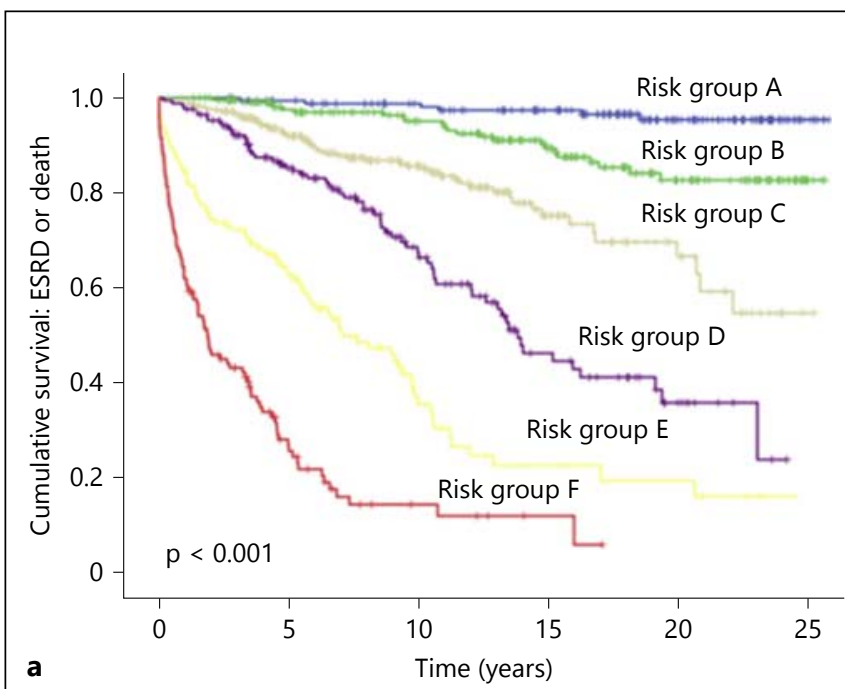

a

Risk group A

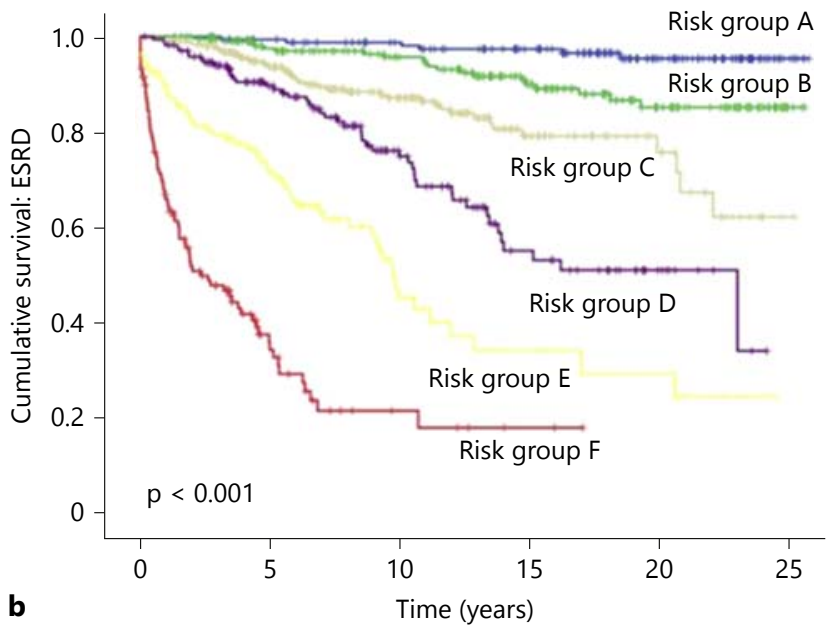

b

Time (years)

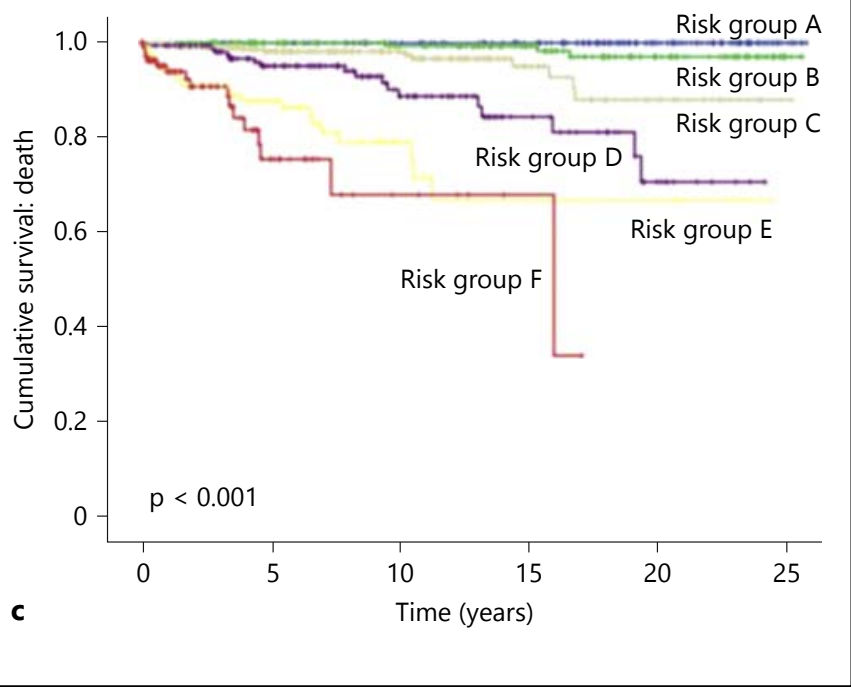

Fig. 2. a-c Kaplan-Meier plots showing cumulative risk of endstage renal disease (ESRD) or death in each risk group (ARR) in the modified ARR model (a), ESRD (b), and death (c). 


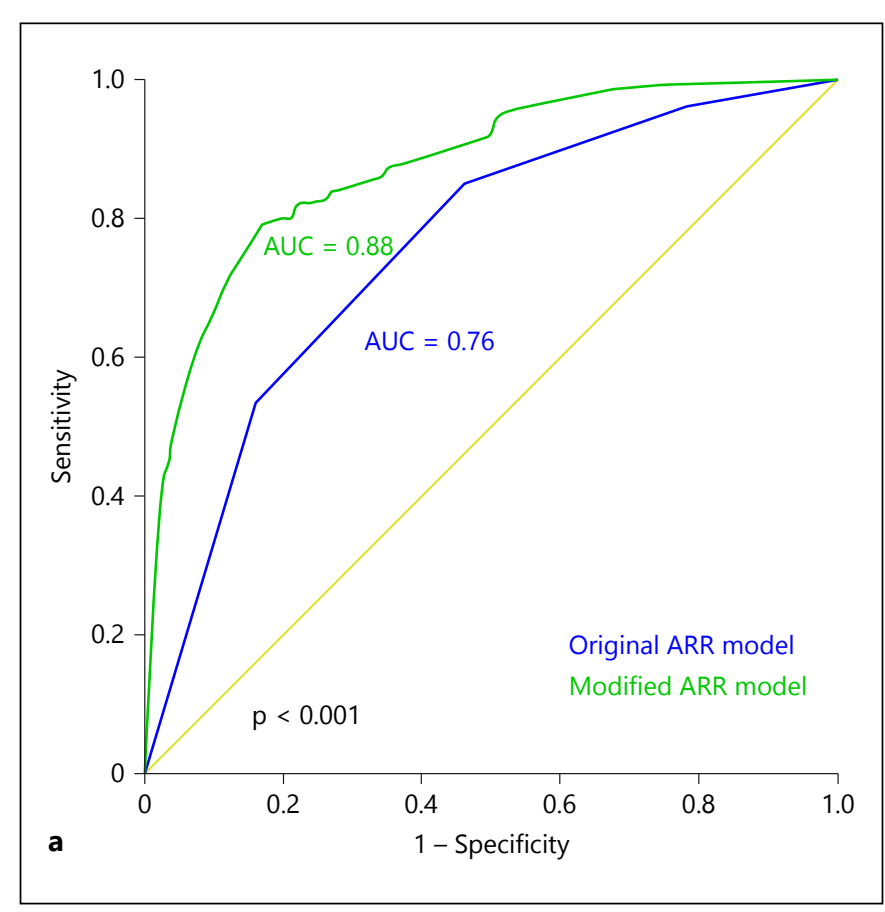

Fig. 3. a-c Receiver operator characteristic (ROC) curves comparing the original ARR model and the modified ARR model at 5, 10, and 15 years at risk, respectively.

model. Obviously, the suggested modified ARR model in the present study needs independent validation in other cohorts and populations before it can be considered a valid prognostic model of IgAN.

IgAN patients are typically characterized by a great heterogeneity in disease presentation and outcome. We have shown that patients with decreased eGFR at diagno-
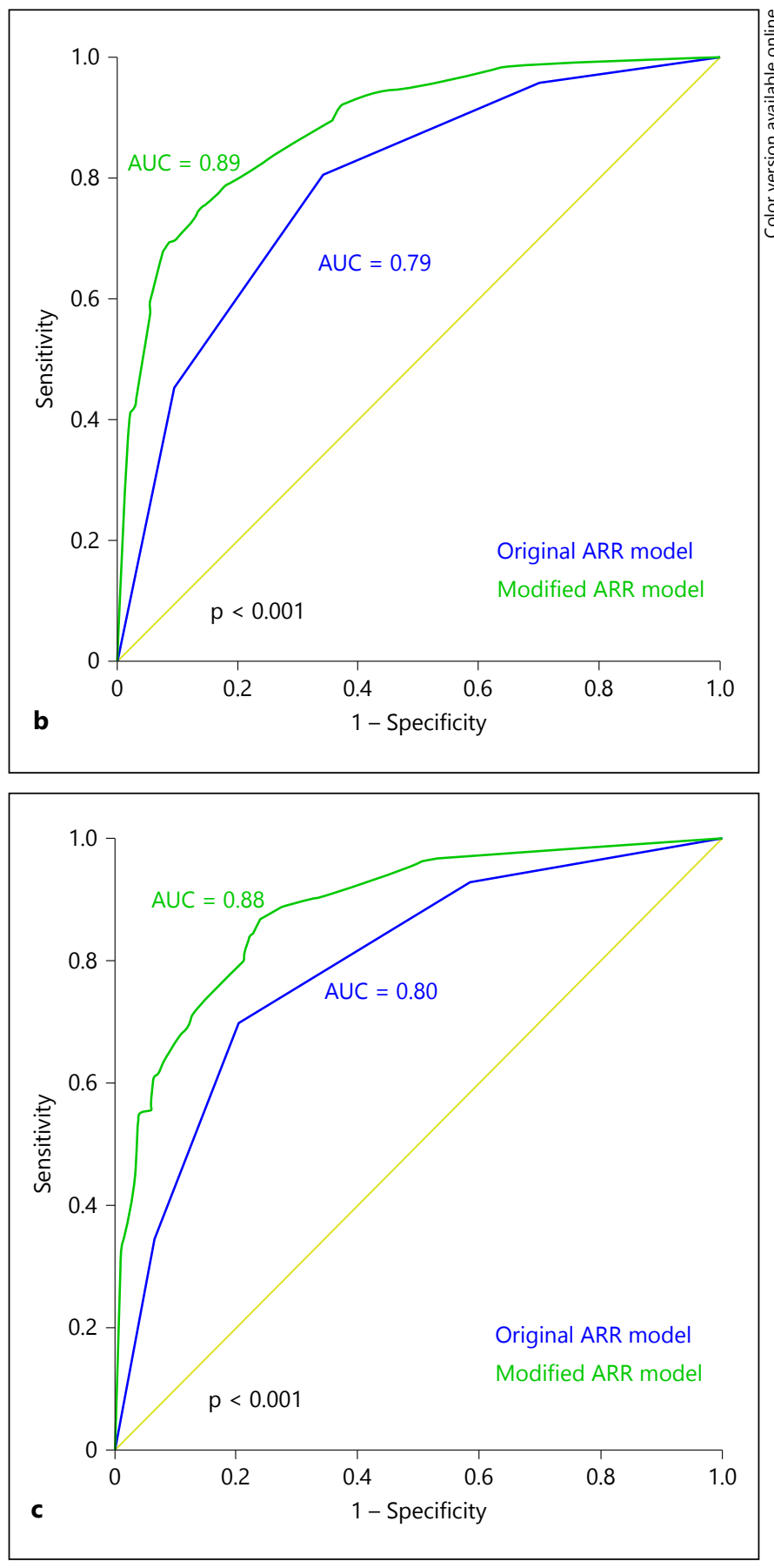

sis usually have a relatively poor long-term prognosis. As shown in the NNTF analysis, the greatest variability in outcome is observed in patients with an initial normal eGFR; this group is therefore the most challenging regarding models for prognostic and therapeutic considerations, and the need for specialist follow-up. Our NNTF data indicates that patients with CKD 1-2 and ARR score 
Table 4. Prognostic abilities of the original ARR model and modified ARR model and evaluation of the number and proportions needed to follow-up to detect an endpoint during the first 15 years of follow-up

\begin{tabular}{|c|c|c|c|c|c|c|c|}
\hline Cohort & Groups & $\begin{array}{l}\text { Total, } \\
\mathrm{n}\end{array}$ & $\begin{array}{l}\text { ESRD } \\
\text { or } \\
\text { death, } \\
n\end{array}$ & $\begin{array}{l}\text { Cumulative } \\
\text { risk of ESRD } \\
\text { or death } \\
15 \text { years, } \%\end{array}$ & $\begin{array}{l}\text { DR, } \\
\%\end{array}$ & $\begin{array}{l}\text { Cohort, } \\
\%\end{array}$ & NNTF \\
\hline \multirow{4}{*}{$\begin{array}{l}\text { Original } \\
\text { ARR } \\
\text { model }\end{array}$} & 0 & 185 & 14 & 6 & 100 & 100 & 16.7 \\
\hline & 1 & 314 & 57 & 21 & 96 & 84 & 4.8 \\
\hline & 2 & 375 & 116 & 43 & 78 & 56 & 2.3 \\
\hline & 3 & 260 & 133 & 60 & 42 & 23 & 1.7 \\
\hline \multirow{6}{*}{$\begin{array}{l}\text { Modified } \\
\text { ARR } \\
\text { model }^{*}\end{array}$} & A & 168 & 6 & 3 & 100 & 100 & 33.3 \\
\hline & B & 226 & 23 & 11 & 98 & 85 & 9.1 \\
\hline & $\mathrm{C}$ & 318 & 54 & 25 & 91 & 65 & 4.0 \\
\hline & $\mathrm{D}$ & 169 & 65 & 55 & 74 & 37 & 1.8 \\
\hline & $\mathrm{E}$ & 134 & 79 & 77 & 54 & 22 & 1.3 \\
\hline & $\mathrm{F}$ & 119 & 93 & 88 & 29 & 10 & 1.2 \\
\hline
\end{tabular}

* Table $3 b$ shows the stratification of cohort based on modified ARR model.

$\mathrm{DR}=$ Detection rate (i.e., the proportion (\%) of detected cases of ESRD/death if all with at least this value were followed). Cohort (i.e., the proportion (\%) of cohort needed to be followed up if all with at least this value were followed). NNTF (i.e., numbers needed to follow, how many patients are needed to be followed up to detect one patient with endpoint).

Table 5. Comparison of baseline characteristics and cumulative risk of the combined endpoint of ESRD/death between the French [reference] and Norwegian IgAN cohorts

\begin{tabular}{|c|c|c|c|c|c|c|}
\hline & \multicolumn{2}{|c|}{$\%$ of patients } & \multicolumn{4}{|c|}{ Cumulative risk of ESRD/death after kidney biopsy } \\
\hline & \multirow[t]{2}{*}{ French } & \multirow[t]{2}{*}{ Norwegian } & \multicolumn{2}{|c|}{5 (10)-year* } & \multicolumn{2}{|c|}{15 (20)-year* } \\
\hline & & & French & Norwegian & French & Norwegian \\
\hline $\mathrm{ARR}=0$ & 46 & 19 & 2 & 3 & 4 & 6 \\
\hline $\mathrm{ARR}=1$ & 21 & 30 & 2 & 6 & 9 & 21 \\
\hline $\mathrm{ARR}=2$ & 20 & 27 & 7 & 17 & 18 & 43 \\
\hline $\mathrm{ARR}=3$ & 14 & 23 & 29 & 39 & 64 & 60 \\
\hline Initial eGFR $<60$ & 26 & 38 & & & & \\
\hline
\end{tabular}

* In the French study, time zero was the onset time of the disease, a date that preceded the diagnostic biopsy with a mean of 5.5 years. In the Norwegian cohort time, zero was the date the diagnostic kidney biopsy was performed. As a result, we have compared 5 and 15 years outcome in the Norwegian with 10 and 20 years outcome in the French cohort.

0-1 probably do not need specialist follow-up after the kidney biopsy. Two limitations deserve attention. First, it is unknown to what extent treatment and specialist follow-up have contributed to the low risk of these patients. Second, as IgAN is mostly diagnosed in young patients even a follow-up of up to 15 years may be insufficient to draw conclusions about the life-time risk of ESRD in these patients.

eGFR and Age in the Prognosis of IgA Nephropathy
Cumulative risks of ESRD/death with ARR score 0 and 3 were approximately similar in the Norwegian and the French cohorts. With an ARR score of 1 and 2, the risks were substantially higher in the Norwegian cohort. It is possible that a higher fraction of patients with eGFR $<60$ $\mathrm{ml} / \mathrm{min} / 1.73 \mathrm{~m}^{2}$ and ARR score 1 and 2 in the Norwegian cohort can explain this finding. A direct comparison was unfortunately not possible because cumulative risk in the 
French study separately for different strata of initial eGFR was not reported.

We must emphasize that we were not able to validate all aspects of the ARR prognostic model due to the nature of our database. First, in the French study time zero was onset of the disease, a date that preceded the diagnostic biopsy with a mean of 5.5 years. In the Norwegian cohort time, zero was the date the diagnostic kidney biopsy was performed. As a result, we have compared 5 and 15 years outcome in the Norwegian with 10 and 20 years outcome in the French cohort. Second, the definition of severe histopathological lesions is different between the studies. Due to data registration in the NKBR it was not possible to apply the global optical score (GOS) that is used in the French study. However, the same histological parameters (glomerular, vascular, and tubulointerstitial) are used in both GOS and the histological grading system of the present study and the difference is thus probably relatively limited. Finally, the definition of proteinuria $\geq 1 \mathrm{~g} / 24 \mathrm{~h}$ was based on urine dipstick test or clinical information in $20 \%$ of the Norwegian patients; in the French study, all patients had quantitatively measured proteinuria. Apart from these corrections, we consider our study as a strong external validation of the ARR prognostic model as described by Berthoux et al. [17].

In the French study, progression to Chronic Kidney Disease (CKD) 3 or higher is an additional end-point to ESRD/death and therefore, it could not also serve as a risk factor in the ARR model. We could not apply CKD 3+ as an end point in our study because there are no follow-up data on kidney function in the NKBR database. Considering the complete biological course of IgAN, we agree with Berthoux et al. that a low initial eGFR is in fact a damage marker that suits as an end-point and not a risk factor of this disease. However, since IgAN initially often is an asymptomatic condition, it is frequently not detected clinically until late in the natural disease course. Thus, lead time bias is obviously a complicating factor in the assessment of prognosis in IgAN patients. Nevertheless, in clinical practice and as shown in the present study, a low eGFR at the time of the diagnostic kidney biopsy is an important prognostic marker regarding the future risk of ESRD/death.

In contrast to another recently published prognostic model on IgAN patients [17], deaths occurring before the commencement of renal replacement therapy were included in the current study as a primary endpoint in the ARR model. The rationale was the high mortality rate observed in chronic kidney disease patients in general [15]; surprisingly, the same picture is not observed in patients with chronic kidney disease resulting from IgAN. In both the French and the current cohorts, cases of ESRD greatly outnumbered deaths. In the French study, 32 ESRD and 13 deaths [14] were observed, compared to 251 ESRD and 69 deaths as observed in the present work. Furthermore, our group recently demonstrated that the mortality rate of IgAN patients with initial eGFR in the normal range is not increased compared to the general population adjusted for age and sex [21]. Thus, it may be disputable whether including deaths as an endpoint in the ARR model is appropriate, particularly when applied for patients with eGFR $\geq 60 \mathrm{ml} / \mathrm{min} / 1.73 \mathrm{~m}^{2}$.

In addition to improved prognostic capacity, the modified ARR score also has other advantages compared to the original ARR model. For example, a patient with proteinuria $\geq 1 \mathrm{~g} / 24 \mathrm{~h}$ and an aggressive histological picture but no other risk factors has a modified ARR score of 5.0 $(2.1 \times 2.4)$. The hazard value for this person is 5.0 times the hazard value for a person with none of the risk factor apparent. Furthermore, the hazard value for a person with a score of 5.0 is $1.7(5.0 / 2.9=1.7)$ times the hazard value for a patient who has a score of 2.9. With the original ARR model, the score (0-3) does not contain direct relative risk information. In total, there are 48 possible scores with the modified ARR model; some practitioners might find it useful to stratify the patients into fewer risk groups. We therefore also stratified the modified ARR scores into six groups equally spaced on a logarithmic scale.

The obvious strength of our study is the large population-based patient cohort with very long follow-up time and many endpoints. A weakness is the lack of information regarding how the patients were treated; such information is not available in the NKBR. In the French cohort, all patients were reported to have received adequate treatment; this is likely the case also in Norway since nephrologists in general oversee the follow-up of IgAN patients. There are, however, no clear guidelines on treatment of high-risk IgAN patients and differences in treatment protocols are therefore likely. It is also a weakness of both the present and the French study that the Oxford classification of IgAN [23] was not used to define severe histological lesions. It must, however, be noted that most patients in both studies were diagnosed prior to the publication of the Oxford classification and retrospective use of this classification on registry data is not feasible. Second, there is obviously substantial overlap between the Global Optical Score (GOS), the definition of severe histological lesions in the present study and the Oxford classification. Third, the Oxford Classification of IgAN was not developed for IgAN patients with low-grade protein- 
uria nor for patients with advanced kidney failure (eGFR $<30 \mathrm{ml} / \mathrm{min} / 1.73 \mathrm{~m}^{2}$ ).

Receiving operating characteristic (ROC) curves were used to evaluate the performance of the modified ARR score resulting in improved AUC values indicating that the model has a strong potential as a prognostic model for 5-15 years survival. Note however that the derived AUC is subject to being overly optimistic because it is derived from the same data as was used to fit the Cox model.

Time has perhaps come to suggest that there is a need for collaborative efforts aiming at developing a single and internationally accepted prognostic model incorporating both histological and clinical risk factors of this disease.

In summary, we have shown that the ARR model is applicable to predict prognosis regarding the risk of ESRD and deaths in a Norwegian IgAN cohort. Inclusion of eGFR and age at time of diagnosis substantially improves the accuracy of the model, and may reduce the cost of un- necessary specialist follow-up of low-risk patients. Excluding deaths as an endpoint should be considered when the ARR model is applied on IgAN patients with normal initial eGFR.

\section{Transparency Declaration}

The lead author, Thomas Knoop, affirms that this manuscript is an honest, accurate, and transparent account of the study being reported; that no important aspects of the study have been omitted; and that any discrepancies from the study as registered have been explained. The results presented in this paper have not been published previously, except some of the data were presented as a poster on the EDTA meeting in Paris 2012.

\section{Disclosure Statement}

None declared.

\section{References}

1 D'Amico G: The commonest glomerulonephritis in the world: IgA nephropathy. Q J Med 1987;64:709-727.

$>2$ Floege J, Feehally J: IgA nephropathy: recent developments. J Am Soc Nephrol 2000;11: 2395-2403.

-3 Levy M, Berger J: Worldwide perspective of IgA nephropathy. Am J Kidney Dis 1988;12: 340-347.

-4 Barbour SJ, Reich HN: Risk stratification of patients with IgA nephropathy. Am J Kidney Dis 2012;59:865-873.

5 Canetta PA, Kiryluk K, Appel GB: Glomerular diseases: emerging tests and therapies for IgA nephropathy. Clin J Am Soc Nephrol 2014;9:617-625.

6 Wyatt RJ, Julian BA: IgA nephropathy. N Engl J Med 2013;368:2402-2414.

7 Alamartine E, Sabatier JC, Guerin C, Berliet JM, Berthoux F: Prognostic factors in mesangial IgA glomerulonephritis: an extensive study with univariate and multivariate analyses. Am J Kidney Dis 1991;18:12-19.

8 Chacko B, John GT, Neelakantan N, et al: Presentation, prognosis and outcome of IgA nephropathy in Indian adults. Nephrology (Carlton) 2005; 10:496-503.

-9 D'Amico G: Influence of clinical and histological features on actuarial renal survival in adult patients with idiopathic IgA nephropathy, membranous nephropathy, and mem- branoproliferative glomerulonephritis: survey of the recent literature. Am J Kidney Dis 1992;20:315-323.

10 D'Amico G: Natural history of idiopathic IgA nephropathy: role of clinical and histological prognostic factors. Am J Kidney Dis 2000;36: 227-237.

11 Donadio JV, Grande JP: IgA nephropathy. N Engl J Med 2002;347:738-748.

12 Geddes CC, Rauta V, Gronhagen-Riska C, et al: A tricontinental view of IgA nephropathy. Nephrol Dial Transplant 2003;18:1541-1548.

13 Johnson ES, Thorp ML, Yang X, Charansonney OL, Smith DH: Predicting renal replacement therapy and mortality in CKD. Am J Kidney Dis 2007;50:559-565.

14 Berthoux F, Mohey H, Laurent B, Mariat C, Afiani A, Thibaudin L: Predicting the risk for dialysis or death in IgA nephropathy. J Am Soc Nephrol 2011;22:752-761.

15 Go AS, Chertow GM, Fan D, McCulloch CE, Hsu CY: Chronic kidney disease and the risks of death, cardiovascular events, and hospitalization. N Engl J Med 2004;351:1296-1305.

-16 Tripepi G, Heinze G, Jager KJ, Stel VS, Dekker FW, Zoccali C: Risk prediction models. Nephrol Dial Transplant 2013;28:19751980.

17 Goto M, Wakai K, Kawamura T, Ando M, Endoh M, Tomino Y: A scoring system to predict renal outcome in IgA nephropathy: a nationwide 10 -year prospective cohort study. Nephrol Dial Transplant 2009;24:30683074.

18 Churg J: IgA nephropathy; in Glassock R (ed): Renal Disease-Classification and Atlas of Glomerular Diseases, ed 2. New York, Tokyo, IGAKU-SHOIN, 1995, p 181.

19 Wakai K, Kawamura T, Endoh M, et al: A scoring system to predict renal outcome in IgA nephropathy: from a nationwide prospective study. Nephrol Dial Transplant 2006; 21:2800-2808.

20 Bjørneklett R, Vikse BE, Bostad L, Leivestad $\mathrm{T}$, Iversen BM: Long-term risk of ESRD in IgAN; validation of Japanese prognostic model in a Norwegian cohort. Nephrol Dial Transplant 2012;27:1485-1491.

21 Knoop T, Vikse BE, Svarstad E, Leh S, Reisæter AV, Bjørneklett R: Mortality in patients with IgA nephropathy. Am J Kidney Dis 2013;62:883-890.

22 Mohey H, Laurent B, Mariat C, Berthoux F: Validation of the absolute renal risk of dialysis/death in adults with IgA nephropathy secondary to Henoch-Schönlein purpura: a monocentric cohort study. BMC Nephrol 2013;14:169.

23 Cattran DC, Coppo R, Cook HT, et al: The Oxford classification of IgA nephropathy: rationale, clinicopathological correlations, and classification. Kidney Int 2009;76:534-545. 